\title{
O LUGAR DO SABER NA PSICANÁLISE E NA UNIVERSIDADE E SEUS EFEITOS NA EXPERIÊNCIA DO ESTÁGIO NAS CLÍNICAS-ESCOLA
}

Vinicius Anciães Darriba

Vinicius Anciães Darriba Professor adjunto do Departamento de Psicologia da Universidade Federal do Paraná; doutor em Teoria Psicanalítica pela Universidade Federal do Rio de Janeiro; psicanalista.

RESUMO: Este artigo retoma o debate sobre as relações entre a psicanálise e a universidade, enfocando a experiência do estágio clínico nas clínicas-escola dos cursos de graduação em Psicologia. Busca-se trazer para este contexto as contribuições de Lacan quanto ao lugar do saber na psicanálise e na ciência, bem como na distinção entre um discurso universitário e um discurso do analista. No âmbito de tal experiência, serão discutidos, ainda mais especificamente, os efeitos do término do atendimento, que, no caso, está associado à saída do estagiário.

Palavras-chave: Psicanálise, universidade, ciência, saber, estágio clínico.

ABSTRACT: The importance of knowledge on psychoanalysis and the university and its effects on the experience of internship on university practices. This article resumes the debate about the relationship between psychoanalysis and the university, conducting it towards the experience of the clinical internship on the university practices of the psychology graduation courses. It aims to bring to this context, the contributions of Lacan as to the importance of knowledge in psychoanalysis and in science, as well as in the distinction between a university discourse and a psychoanalyst discourse. Within the scope of the clinical internship experience, there will be discussions, more specifically, on the effects of the termination of the treatment that in this case, is associated to the departure of the intern.

Keywords: Psychoanalysis, university, science, knowledge, clinical internship. 


\section{INTRODUÇÃO}

Muito se tem escrito sobre a relação entre a psicanálise e a universidade, o que é compatível com a presença nesta daquela, em particular nos cursos de graduação em Psicologia. A discussão em torno deste tema tende a enfatizar a tensão que subsiste a tal relação. Tensão que não é tomada como índice de que algo vai mal nesta relação, mas como efeito de posições que se revelam antagônicas, principalmente no que diz respeito ao lugar consagrado ao saber em uma e em outra. Embora a reflexão sobre a psicanálise na universidade tenha se iniciado cedo - o próprio Freud ocupando lugar de pioneirismo na abordagem do tema ${ }^{1}$ —, a identificação por Lacan dos quatro discursos que definem as modalidades de laço social na cultura, distinguindo, além dos discursos do mestre e da histérica, o discurso universitário e o discurso do analista, estabeleceu um terreno privilegiado para que os impasses do encontro entre estes últimos pudessem ser pensados.

Os impasses se fazem visíveis na relação entre a psicanálise e o modo como se concebe, na universidade, seja o ensino, seja a pesquisa, seja, acrescentaremos aqui, a formação para o exercício da prática clínica. Neste artigo, retornaremos ao debate que opõe o discurso do analista ao discurso universitário, mas com o intuito específico de examinar o que se observa na experiência do estágio clínico realizado nas clínicas-escola das universidades, vinculadas aos cursos de graduação em psicologia. Mais especificamente, buscaremos articular à discussão mais geral certos efeitos perceptíveis do fato de que, nesta experiência, a duração dos atendimentos realizados pelos estagiários é limitada pelo término do período do estágio. ${ }^{2}$

\section{PSICANÁLISE E CIÊNCIA, PSICANÁLISE E UNIVERSIDADE, MAIS UMA VEZ}

Foi em torno do lugar ocupado pelo saber que Lacan (1966), em grande medida, articulou a questão do sujeito na psicanálise com a operação própria à ciência designada moderna, hegemônica a partir do século XVII. Novamente, o lugar do saber foi decisivo quando se tratou de demarcar a diferença, no interior da teoria

\footnotetext{
${ }^{1}$ Em 1919 foi publicada, sob forma de artigo, a tradução para o húngaro de um trabalho, provavelmente concebido no ano anterior, em que Freud se interroga sobre a conveniência do ensino da psicanálise nas universidades (FREUD, 1919 [1918]/1990). Strachey indica que neste período havia uma agitação entre os estudantes de medicina de Budapeste quanto à inclusão da psicanálise no currículo.

2 Tais efeitos foram investigados, no ano de 2007, em pesquisa que contou com alunas de iniciação científica (Joanna Franco Gonçalves Vieira, Juliana Masioli Guimarães, Narcisa Castilho Melo e Renata Coelho), graduandas do curso de psicologia da Universidade Estácio de Sá no campus Niterói/RJ, onde a prática da psicanálise na clínica-escola nos serviu de campo para a investigação.
} 
dos quatro discursos, entre o discurso universitário e o discurso do psicanalista (1969-70). Não devemos nos apressar em concluir, no entanto, que a estrutura do discurso universitário recobre, no ensino de Lacan, aquilo que caracteriza para ele a ciência. Miller indica que a universidade, identificada a certo modo de recolher, ordenar e transmitir o saber, não acolhe todos os saberes, só os que lhe convém (MILLER, 1997, p.112). Lembra, ainda, que ela nasceu na Idade Média, da iniciativa do poder político, e que a física e a matemática, por exemplo, se abstiveram durante muito tempo da inscrição universitária (idem, p.113).

Abordaremos em separado, então, o modo como aprendemos a pensar, com Lacan, a relação entre a psicanálise e a ciência, de um lado, e a relação entre a psicanálise e a universidade, de outro. As similitudes entre as duas articulações não deixarão de comparecer.

No que diz respeito à relação entre a psicanálise e a ciência, partiremos de Freud, com o intuito de demarcar como o intervalo de tempo entre ele e Lacan conduziu a uma diferença na abordagem do tema. Para avançar de Freud a Lacan, seguiremos a pista de Jean-Claude Milner (1996), que associa as hipóteses de Lacan à reflexão epistemológica própria a seu tempo. A referência aí é Koyré, que, criticando uma concepção positivista da ciência, familiar a Freud, enfatizou a matematização da realidade como o que distingue a ciência moderna. Milner estabelece uma conexão entre este traço definidor, segundo Koyré, do modo como opera a ciência moderna e a proposição de Lacan segundo a qual tal operação condiciona o advento do sujeito implicado na práxis da psicanálise.

Iniciando, então, pela reflexão freudiana concernente à relação entre a psicanálise e a ciência, restringiremos nosso foco à conferência sobre a Weltanschauung, ${ }^{3}$ de 1932. Entendemos que tal redução se presta a evidenciar que representação de ciência, ocupando um lugar de ideal para a psicanálise, vigora ainda tardiamente na obra de Freud. Em dado momento da conferência, ele afirma, com respeito ao trabalho científico, que:

“Seu esforço é no sentido de chegar à correspondência com a realidade — ou seja, com aquilo que existe fora de nós e independentemente de nós, e, segundo nos ensinou a experiência, é decisivo para a satisfação ou a decepção de nossos desejos. A essa correspondência com o mundo externo real chamamos de 'verdade',' (idem, p.207)

\footnotetext{
${ }^{3}$ Freud define a expressão alemã nestes termos: "uma construção intelectual que soluciona todos os problemas de nossa existência, uniformemente, com base em uma hipótese superior dominante, a qual, por conseguinte, não deixa nenhuma pergunta sem resposta e na qual tudo o que nos interessa encontra seu lugar fixo" (FREUD, 1933[1932]/1990, p.193). Entende que, embora faça referência a uma Weltanschauung científica como aquela que deve ser acatada pela psicanálise, tal definição geral diverge em muito daquilo que, na ciência, lhe equivaleria, e que seria, no caso, marcado por características negativas e formas limitadas de conhecimento (idem, p.194).
} 
Freud afirma, então, que o objetivo do conhecimento científico é a correspondência com a realidade, a qual é definida como o que existe 'fora de nós e independentemente de nós'. A tal correspondência ele dá o nome de 'verdade'. A aproximação proposta na conferência entre a psicanálise e a Weltanschauung científica, ${ }^{4}$ tomada nestes termos, estabelece óbvias dificuldades para a psicanálise conceber em que consistiria tal realidade 'fora de nós' a que visaria e em tomar a verdade como tal. Em outro momento, tais questões foram por nós discutidas (DARRIBA, 2003, p.165-181). Neste artigo, no entanto, o que nos interessa é a associação proposta por Freud entre a ciência e o conhecimento da realidade, a qual aparecerá em Koyré como eixo da problematização que propõe no campo da epistemologia.

Para Koyré, a ciência moderna se funda por meio da matematização da realidade. Todavia, ele entende ser necessário retroceder às origens da atitude filosófica, para identificar a mutação que foi preciso haver para o nascimento da ciência moderna nos moldes de uma física matemática (KOYRÉ, 1961b, p.272). Se partimos de Platão e Aristóteles, verificamos que a realidade a que o pensamento racional tinha acesso não era a deste mundo fenomenal em que nos movemos, mas a de um mundo à parte, em que as Ideias ou as Essências eram as entidades conformes à razão. Na medida que tais entidades só se realizam imperfeitamente no mundo em que vivemos, a razão não encontrava nele a precisão que a define. A realidade física, portanto, diz respeito ao domínio do impreciso, e sendo as noções matemáticas o retrato mais fiel da precisão, da regularidade, a matemática não se aplicava a uma física.

Pelo fato de a ciência moderna ter sido fundada, segundo Koyré, através da matematização da realidade, esta dependeu de que a ideia da precisão passasse a ser aplicável ao mundo em que nos movemos. É porque esta atribuição está ausente do pensamento grego e de sua herança que a ciência moderna exigiu uma transformação de atitude filosófica. Um abismo era percebido entre a matemática e a realidade física. A esta última se referia justamente o movediço, o impreciso, o 'mais-ou-menos', como diz Koyré. A regularidade dos círculos, das elipses, das retas, não era encontrada. Já nos Céus, se entendia que os movimentos regulares estariam presentes. O cuidado e a dedicação da ciência grega em estabelecer uma astronomia matemática não encontrou paralelo na física, devido exatamente à compreensão de que o movimento terrestre não se presta à matematização.

Na mesma medida em que toma a matematização da realidade como o principal fator na origem da ciência moderna, Koyré critica a interpretação positivista de tal origem, que atribui mais valor ao papel da experiência. Ele não nega o caráter

\footnotetext{
${ }^{4} \mathrm{Na}$ conclusão do trabalho, Freud propõe, por exemplo, que a psicanálise "é incapaz de criar uma Weltanschauung por si mesma", que ela "não precisa de uma Weltanschauung; faz parte da ciência e pode aderir à Weltanschauung científica" (idem, p.220).
} 
empírico da ciência moderna, mas entende que no método experimental, tal como estabelecido por Galileu, a teoria matemática determina a própria estrutura da pesquisa (KOYRÉ, 1966, p.74). Koyré denuncia que a importância das experiências cuja realização se atribui a Galileu é superestimada — experiências não precisas, não realizáveis nas condições de que dispunha e, até mesmo, supostas de demonstrarem proposições que não seriam, de fato, observáveis.

O problema maior de tal deformação da história, segundo Koyré, é que ela sustenta a recusa positivista em conhecer o real, preservando a operação no nível dos fenômenos. O nascimento da doutrina positivista é situado por ele na atitude da astronomia grega de, "diante da incapacidade de penetrar no mistério dos verdadeiros movimentos dos corpos celestes", limitar-se a tratar os dados da observação de maneira formal (idem, p.73). Com esta atitude, fica conservada a possibilidade de se fazer predições válidas, mas ao preço do divórcio entre a teoria matemática e a realidade subjacente. Koyré entende, em oposição, que a ciência deve ter sempre como horizonte o conhecimento do real. De acordo com este ponto de vista, sua crítica ao positivismo acusa-o de ser "filho do fracasso e da renúncia" (idem, p.72).

O que é fundamental frisar na proposta de Koyré é que a ciência sustentar o conhecimento do real, em oposição à perspectiva positivista, não significa a crença em uma harmonia prévia entre a matemática e a realidade. O problema, para Koyré, não é que se considere aparentemente inútil ou impossível o objetivo de conhecer o real. O problema, uma diferença sutil que o autor estabelece, é renunciar a tal objetivo (idem, p.75). A renúncia positivista é, para ele, uma posição de recuo de curta duração de um espírito humano que, na verdade, nunca aceita tal posição. Espírito humano que acaba se pondo "outra vez a procurar a solução inaproveitável, ou impossível de problemas considerados como desprovidos de sentido" (KOYRÉ, 1961a, p.212). Que a ciência persiga a explicação real das leis que propõe não pode ser questionado, já que é esta a própria operação que a define.

Se a ciência moderna, nos termos de uma física matemática, não apresenta um acordo imediato com a experiência comum, trata-se de redefinir a realidade que experimentamos. Um corpo que é arremessado, por exemplo, não se mantém em um movimento retilíneo permanente. Matematizar a realidade é determinar para ela uma estrutura adequada a uma ciência matemática. Koyré indica, na origem da ciência moderna, o estabelecimento do espaço abstrato da geometria euclidiana como real (idem, p.205). Não é por postular a preexistência de uma realidade matematizável que a ciência avança, mas exatamente por persegui-la, construindo esta realidade de estrutura matemática. Os objetos que habitam 
esta realidade se adequam à ciência por serem objetos por ela introduzidos. ${ }^{5}$ Ela insere na realidade os objetos que a transformam em uma realidade com a qual o conhecimento científico venha a coincidir.

Até aqui, com base em Koyré, vimos a ciência moderna se fundar na matematização da realidade. Concluímos, a partir daí, pela distinção de duas perspectivas: uma em que a adequação do conhecimento científico — formulado em termos matemáticos — com a realidade é suposta preexistente; e outra em que é o objetivo, que não pode ser abandonado pela ciência, de se adequar à realidade que impõe a esta última uma estrutura matemática. É pela segunda perspectiva que se pode, evitando a resignação da interpretação positivista, associar a ciência moderna ao conhecimento do real, sem que isto implique a crença, conforme a primeira perspectiva, em uma essência comum ao pensamento e à realidade. Veremos, a seguir, em que termos Jean-Claude Milner, em sua leitura de Koyré e mirando Lacan, estabelece uma distinção para a qual converge o que até aqui encaminhamos.

Milner parte da observação de Koyré de que os dois traços que, combinados, definem a ciência moderna são a 'empiricidade' e a 'matematicidade' (MILNER, 1996, p.50). Mas a associação da matemática, do Número, ${ }^{6}$ com o necessário e o eterno, que é herdada dos gregos, se confronta com a propriedade do empírico de estar sempre vindo a ser ou deixando de ser. Sendo então o empírico intrinsecamente antimatemático, como é abarcado por uma ciência matemática? Recorrendo à epistemologia de Popper, ${ }^{7}$ Milner introduz no problema a noção de contingência. Para isto, se volta de início para a questão da refutabilidade, tal como se apresenta na teoria de Popper.

Segundo Popper, o que determina uma proposição científica é sua refutabilidade. Ou seja, o que define o status científico de uma teoria é sua capacidade de ser refutada (POPPER, 1972/1982, p.66). Entende-se como refutável a proposição cuja negação não é logicamente contraditória nem invalidada pela observação. Nos termos que interessam a Milner, a refutabilidade implica que o referente da proposição "deve poder - lógica ou materialmente - ser outro que é" (MILNER, 1996, P.50), o que é a própria definição da contingência. É deste modo que ele conclui que a ciência é sempre ciência do contingente. Retomando o problema acima, o que deve ser conciliado, portanto, é uma ciência matemática com uma ciência do contingente.

\footnotetext{
${ }^{5}$ Koyré nos dá o exemplo do relógio cronométrico, cuja invenção não se dá na prática dos relojoeiros, mas na pesquisa dos homens de ciência. A relojoaria de precisão não é fruto de uma necessidade que pudesse ser atribuída a questões práticas cotidianas. Ela responde à necessidade de realização da teoria.

${ }^{6}$ Conservamos aqui o uso da maiúscula adotado pelo autor.

${ }^{7}$ Milner reconhece a distância entre as epistemologias de Koyré e de Popper, que, no entanto, aqui são cruzadas.
} 
A ciência matemática deve apreender o contingente como tal. E, por isso, Milner prefere falar de uma ciência 'matematizada', em que não se trata mais do Número e de sua fixidez, mas da letra matemática (MILNER, 1991, p.340). A ciência moderna tem como correlato um empírico literalizável. Se a letra da lei da ciência remete ao necessário, é por uma operação distinta da que associa a ideia de necessidade à matemática herdada dos gregos. Se, neste segundo caso, lidamos com o eterno, com o que não pode ser outro que é, no caso da matemática captando o diverso como letra, não se nega sua condição de poder ser outro que é. A letra fixada assume, por certo, os traços da imutabilidade, mas não há uma razão para que seja como é. A imutabilidade que a própria operação da letra matemática na ciência impõe difere da imutabilidade que deve ser postulada em função de algo anterior e eterno. Reencontra-se, assim, em outros termos, a diferença que estabelecemos entre, de um lado, a adequação do-conhecimento científico à realidade ser tomada como preexistente e, de outro, ela ser resultado do próprio procedimento científico.

A captação do diverso pela letra, conjugando necessidade e acaso, relacionando o necessário e o contingente, conduz Milner a Mallarmé. É tomando a letra como o 'lance de dados'8 que ele pode enunciar o status do necessário sem a abolição do contingente. Os dois momentos do lance de dados são os dados lançados e os dados que caem em uma combinação. Na problemática que Milner tenta elucidar, trata-se do momento que "cada ponto de cada referente de cada proposição da ciência surge como podendo ser infinitamente outro que é” e do momento que a letra o fixa como não podendo ser outro que é (MILNER, 1996, p.52). Os dados lançados são a afirmação do contingente, sua combinação ao cair, a afirmação da necessidade, sendo um momento condição do outro. A necessidade afirmada não resulta, então, na abolição da contingência. Mas, apesar disso, a ciência supõe que a letra assuma a aparência da imutabilidade.

Na ciência, portanto, a letra fixada tenta impor o esquecimento da contingência. A necessidade de suas leis se propõe como cicatriz da contingência. Definindo como a emergência do sujeito o intervalo de tempo em que os dados estão em suspensão (idem), ${ }^{9}$ Milner direciona a discussão para a fórmula lacaniana segundo a qual a ciência busca suturar seu sujeito (LACAN, 1966, p.875). Para que a letra da ciência assuma os traços do necessário, é preciso não querer saber do que ela arrasta consigo: a contingência que está em sua origem. Nos termos em que Lacan o afirma, a ciência não tem memória, esquece as peripécias de que se originou, negligencia o drama subjetivo do cientista (idem, p.884). ${ }^{10}$

\footnotetext{
${ }^{8}$ Referência ao pensamento de Mallarmé.

${ }^{9}$ Não há um sujeito que lança os dados.

${ }^{10}$ Lacan cita J. R. Mayer e Cantor, cujos dramas conduzem à loucura. Koyré já havia citado o esquecimento promovido pelos sucessores de Newton do lugar ocupado por Deus em sua
} 
Voltando as costas para a aventura subjetiva que está na origem de suas construções, a ciência assume a pretensão, conforme a representação freudiana de que partimos, de que a realidade a que tem acesso seja uma realidade 'independente de nós'. A expressão que Lacan utiliza para caracterizar o procedimento científico é a 'foraclusão' (idem, p.889), no sentido de que a ciência não quer saber de seu sujeito. O sujeito da ciência é suprimido de seu discurso. É este sujeito da ciência, diz Lacan, o sujeito implicado na psicanálise (idem, p.878). Fato distinto, segundo o autor, da questão de saber se a psicanálise é uma ciência. O que é posto em cena é a evidência de que a psicanálise só se concebe com a sutura que a ciência moderna promove no sujeito.

Para Jean-Claude Milner, é Lacan quem sepulta a questão do que deve ser a psicanálise para se adequar à ciência, em favor da pergunta inversa sobre o que seria uma ciência a partir da psicanálise (MILNER, 1996, p.31). Segundo o autor, o que possibilita que esse passo seja dado por Lacan é entender que a ciência não é um ponto exterior ao campo da psicanálise, mas que, "ao contrário, ela estrutura de maneira interna a própria matéria de seu objeto” (idem). A ciência, não sendo ponto exterior ao plano, não pode servir-lhe de regulação. Milner entende que Lacan se distingue de Freud por não acreditar no ideal da ciência para a psicanálise. Em Freud, segundo ele, haveria o ideal da ciência, fundamentando o voto de que a psicanálise seja uma ciência. O ideal da ciência, ponto ideal de convergência de todas as retas do plano, é acompanhado pela ciência ideal, que o determina de modo imaginário. Freud lidaria, portanto, com uma representação do que é a ciência, buscando adequar a psicanálise a ela, ao passo que Lacan se afastaria de tal perspectiva, ao entender que a psicanálise deve encontrar "em si mesma os fundamentos de seus princípios e métodos” (idem).

A aventura subjetiva que a ciência faz questão de esquecer, Lacan destaca ser uma dimensão da verdade que a psicanálise exercita abertamente (LACAN, 1966, p.884). É da verdade como causa, é do que nos causa como sujeitos, o de que a ciência não quer saber. E é disto que se ocupa a psicanálise, deste resto imanente à operação pela qual a ciência supõe possível a coincidência do conhecimento com a realidade. Trata-se de um sujeito dividido, portanto, este de que a psicanálise se ocupa. Ela mostra que o lugar do saber, via de regra, é o lugar daquilo que vem em socorro ao sujeito em sua divisão.

Lacan assevera que o discurso da psicanálise não pode ser o da transmissão de um saber (LACAN, 1969-70/1992, p.188). Ele deve consistir antes no questionamento da função de um certo saber na sociedade. Cabe à psicanálise discutir “a relação do sujeito com o saber e a relação do sujeito com a dimensão da vida

ciência (KOYRÉ, 1961, p.210). Era preciso para estes que a teoria se mantivesse independente do suporte na ideia de Deus. É interessante a constatação do autor de que, privado do suporte divino, o mundo newtoniano se mostra instável e precário. 
que escapa ao saber, ponto limite do sentido” (MAURANO, 2006, p.209). Nos termos em que Lacan articula os quatro discursos em sua teoria, o do psicanalista justamente solicita o saber a funcionar no registro da verdade (LACAN, 1969-70/1992, p.101). Já no discurso universitário, aquele que mostra, segundo Lacan, onde o discurso da ciência se alicerça (idem, p.97), o saber se encontra no lugar do senhor. E esta “nova tirania do saber” é o que o autor afirma tornar “impossível que nesse lugar apareça, no curso do movimento histórico — como tínhamos, talvez esperanças —-, o que cabe à verdade” (idem, p.30).

A posição do saber na psicanálise depende justamente de que este não exclua o sujeito dividido. No discurso universitário, por sua vez, o sujeito dividido renuncia a seu lugar. Diante do mandamento do "Vai, continua. Não para. Continua a saber sempre mais." (idem, p.98), a tomada da palavra é postergada para quando chegar o momento derradeiro da aquisição do saber, momento que nunca chega. Nesta promessa de se produzir como sujeito pensante, o estudante trabalha, por um mais de gozo. O estudante não opera do lugar de sujeito, então, na esperança de vir a se constituir como sujeito da ciência, o que em Lacan define algo da ordem do impossível: que um homem se faça sujeito da ciência.

O que se mascara no discurso universitário é que o saber (S2) opera do lugar de agente porque porta a ordem do mestre (S1), que ocupa o lugar da verdade. Segundo Lacan, "pelo fato de o signo do mestre ocupar esse lugar, toda pergunta sobre a verdade é, falando propriamente, esmagada, silenciada” (idem). Neste sentido, Miller indica só entrarem na universidade os saberes que lhe permitem o mestre (MILLER, 1997, p.112), ainda que este mude no decorrer do tempo. Neste ponto, a psicanálise resiste.

É do lugar de comando ocupado pelo saber no contexto universitário "que surge a inequívoca promessa de, em um movimento progressivo inesgotável, tudo situar sob a sua égide e de tudo se apropriar" (LO BIANCO, 2006, p.7). Isto é o que se apresenta ao estudante, e o que ele espera encontrar ao fim do percurso. O que faz, de mesmo modo, com que a psicanálise porte, na universidade, a marca de um estranhamento, já que, “ao contrário, reconhece sempre algo de irredutível ao saber" (idem).

Sempre aquém da realização da promessa contida no discurso universitário, o trabalho do estudante faz com que este lugar do impossível ganhe contornos de impotência. É pelo compromisso mesmo com a verdade que os quatro discursos definem operações que são impossíveis (LACAN, 1969-70/1992, p.164). Encontram-se aí os ofícios impossíveis que Freud já indicara, em número de três - governar, educar e analisar (FREUD, 1937/1990, p.282) — acrescidos do quarto, fazer desejar, articulado por Lacan ao discurso da histérica (LACAN, 1969-70/1992). Para Lacan, é o discurso analítico que permite vislumbrar que 
algo se dirige ao impossível. Em contraste, a articulação do discurso universitário veste de impotência o que é da ordem de um impossível de saber.

\section{O IMPOSSIVEL DO SABER E A IMPOTÊNCIA DO ESTUDANTE: UMA OBSERVAÇÃO CLÍNICO-ACADÊMICA}

Esta tensão própria à relação entre a psicanálise e a universidade se atualiza quando, ao ocupar a posição de docente na universidade, o psicanalista tem diante de si questões das quais não deve recuar: a possibilidade de operar neste contexto a partir da posição frente ao saber que é própria à psicanálise; os efeitos da incidência do discurso universitário no que se propõe ali como psicanálise; as consequências para a prática clínica de se encontrar inserida entre as atividades formativas de um curso universitário de graduação. Examinaremos aqui a última destas questões, privilegiando nossa experiência como supervisor de acadêmicos de psicologia que, em seus estágios curriculares, tomam como fundamento teórico a psicanálise.

Partindo da diferença na relação ao saber, que não é sem consequências para a práxis da psicanálise na universidade, é possível localizar ainda algumas particularidades deste contexto, cujos efeitos mais agudos se pronunciam na prática clínica dos estágios. Em primeiro lugar, é preciso considerar que a prática clínica nos estágios se apresenta aos estudantes como uma exigência curricular, estando vinculada a elementos estranhos à práxis da psicanálise, como a obrigatoriedade da frequência à supervisão e a delegação ao supervisor da decisão de aprovar ou não o aluno na disciplina de estágio. Entendemos que a vigência de tais condições faz com que a prática clínica em tal contexto corra o risco de submergir na lógica da formação acadêmica, independentemente do modo como atue o supervisor. É fato que, fora dos muros da universidade, em instituições psicanalíticas, pode-se também encontrar, quanto a estes aspectos, uma lógica para a formação não muito distante desta.

Mais importante ainda é considerar que a chegada dos estudantes à clínica, mesmo quando se vai trabalhar a partir da psicanálise, prescinde de um percurso de análise pessoal. Não é da posição de analisante que se chega à clínica, mas da posição de estudante. Entendemos que também aí se imprime sobre essa experiência uma marca que, em alguma medida, independe do manejo da supervisão. A questão de qual seja o alcance de uma clínica psicanalítica sem a exigência da análise pessoal do praticante — invenção dos cursos de formação universitária — nos parece uma questão inóspita, embora entendamos que, desde o campo da psicanálise, seja necessário enfrentá-la. No mínimo, porque falamos de uma clínica que se propõe com o nome da psicanálise, e cuja extensão no meio universitário — e consequentemente na comunidade — é notável. 
Propomos aqui, então, uma reflexão crítica, desde o lugar de supervisor da prática clínica no estágio, acerca das incidências neste dos impasses que pontuam a relação entre a psicanálise e a universidade. Reflexão que, como anunciamos, privilegiará, no âmbito deste artigo, o momento particular do encerramento dos atendimentos. Outras questões que se pronunciam desde o terreno da clínica do estágio, colocando em cena os impasses entre a psicanálise e a universidade, não poderão ser exploradas nos limites do mesmo. Seria o caso, por exemplo, do objetivo com que o estudante se insere na clínica; das ressonâncias entre o discurso universitário e o que se passa também no contexto de formação nas instituições psicanalíticas; das possibilidades da prática da supervisão a partir da psicanálise na clínica-escola. ${ }^{11}$

Este trabalho parte, então, de uma das peculiaridades da prática clínica nos Serviços de Psicologia vinculados a universidades. Nestes locais, os atendimentos são realizados por acadêmicos durante o período que lhes é exigido de estágio curricular. Sendo assim, os atendimentos por eles conduzidos são interrompidos no momento em que encerram seu estágio curricular. ${ }^{12} \mathrm{Na}$ função de supervisor de acadêmicos que estagiam em um destes Serviços de Psicologia, no campo da psicanálise, me deparei com os efeitos na experiência clínica desta situação específica. A investigação realizada buscou pensar tais efeitos em articulação com a psicanálise.

Ao nos aproximarmos daquilo que na experiência da psicanálise neste tipo de instituição nos interessava investigar — os efeitos na clínica do encerramento do estágio - a relação do estagiário com este momento se destacou frente aos próprios efeitos para os pacientes. Nas supervisões e em conversas com os estagiários, a discussão acerca dos efeitos na experiência clínica do término do estágio se reportou invariavelmente à experiência do estagiário. Sendo assim, a reflexão que conduzimos a partir daí buscou articular estes dois aspectos de maneira conceitual.

Em ‘Análise terminável e interminável’ (1937), Freud dedica os últimos parágrafos à discussão de um tema que, na análise de homens e mulheres, ele percebe figurar como fonte de impasses. No caso dos homens, faz referência à luta contra uma atitude passiva e, no das mulheres, à impossibilidade de abdicar ao desejo de um pênis. Freud sintetiza as duas posições em termos de um "repúdio da feminilidade” que ele associa à angústia de castração (FREUD, 1937/1990, p.287). É justamente a partir desta observação final de Freud que vemos Lacan traçar sua conceituação de um fim de análise. Com a diferença de que esse confronto com

\footnotetext{
${ }^{11}$ Em outro momento, este último ponto foi por nós discutido. Ver DARRIBA, 2007.

${ }^{12} \mathrm{O}$ fato de que o paciente pode continuar a ser atendido na instituição por outro estagiário ou procurar futuramente, em outro espaço, o acadêmico que encerrou o estágio não se contrapõe à ideia de que há aí um término do atendimento.
} 
a castração, que aparece como impasse em Freud, indicaria, para Lacan, o ponto preciso ao qual uma análise se dirige, o que não é curável. O processo analítico conduz o sujeito a este ponto em que, no entanto, com um passo a mais, o analisante torna-se analista, o que define, em Lacan, o fim de análise.

A experiência da análise, nos termos da leitura lacaniana, associa-se ao incurável da castração. Ao mesmo tempo, o lugar do analista supõe pôr em ato o que, em sua análise, foi efeito deste encontro. Nessa articulação entre o fim de análise e o tornar-se analista, Lacan faz pensar a experiência analítica como sendo norteada por aquilo que Freud, e depois ele, designam como sendo da ordem da castração, o que se traduz, por exemplo, no impossível de tudo saber.

Uma primeira observação quanto ao manejo do término dos atendimentos pelos estagiários diz respeito à tentativa de amenizar ou mesmo desconsiderar seus efeitos. A possibilidade do paciente — após a saída do estagiário da instituição pelo término do estágio — continuar a ser atendido por outro estagiário na instituição, ou fora dela por aquele que já o atendia, é tomada muitas vezes no sentido de velar o corte que ali se produz. O chamado encaminhamento aparece, então, como uma solução de continuidade que dispensaria estagiário e paciente do trabalho que este corte suscita. Por mais que seja desejável que o período que ali se encerra possa encontrar uma continuidade, esta não apaga o que se produziu neste momento de corte. O encaminhamento não pode servir como solução para tamponar o que se abre neste momento preciso e que, ao invés de prevenção, demanda trabalho.

Não se pode querer promover aí um curto-circuito com o que venha a ser o encaminhamento. Nesta via, o encaminhamento atribuiria àquele que está no lugar de analista e à instituição o poder de trabalhar pelo sujeito. Há algo que só este último poderá encaminhar neste momento, algo que não é antecipável, mas que depende da disponibilidade do estagiário para que possa comparecer. E que comparece de modo singular, no caso a caso. Este momento final do estágio é aquele em que se é, então, convocado mais do que nunca a verificar que o saber do analista não está ali para antecipar sua posição. É quando vem à tona mais claramente a dimensão, em regra ausente do restante da formação universitária, de que algo na experiência clínica resiste à constituição como saber.

Esta experiência, que remonta à castração, se confronta com a demanda ao formando de que o saber adquirido no curso o habilite a dar conta da clínica. Nesta encruzilhada, verifica-se que muitos se refugiam justamente na ilusão de que podem dar conta deste momento sem se haver com a dimensão da castração. ${ }^{13}$ Como neste

\footnotetext{
${ }^{13}$ Outra possibilidade de abordagem do tema seria a discussão da peculiaridade de que o estágio clínico da graduação em psicologia prescinde, formalmente, de que o estagiário esteja em análise pessoal. Esta questão foi aqui deixada de fora, mas nos convoca a pensar o que poderia ser, então, uma clínica psicanalítica neste contexto.
} 
equívoco de, face à saída do analista da instituição, tomar como uma operação capaz de não deixar resto o encaminhamento que possibilitará a continuidade do atendimento. É possível localizar, ainda, no contexto que estamos examinando, outros refúgios frente à castração. Mas antes de fazer referência a eles, vale citar a fala de um paciente quando comunicado da saída do estagiário e da possibilidade de continuar o atendimento com outro. Foi do lado do paciente que a fala se dirigiu ao que a psicanálise enuncia, nos seguintes termos: "Não vai ser igual, não vai ser a mesma coisa". Ou quando perguntado sobre a conveniência de terminar a última sessão em um dado momento: "De que adianta me perguntar?".

Há um trabalho a ser feito neste momento, mas um trabalho que deve partir desta evidência que se reporta à castração: de que algo nunca será o mesmo, de que quanto a alguma perda não adianta. Para que haja trabalho, isso não poderá ser tomado pelo estagiário no registro da impotência, mas do impossível que precisamente convoca ao trabalho. É desta dimensão da castração que o estagiário tenta se desviar quando busca, por exemplo, no caso em que se trata de um paciente cujas sessões giram em torno do tema do abandono, amenizar os efeitos de sua saída. O estagiário tentar fugir à posição do abandonador é fazer supor que ele poderia poupar o paciente da questão do abandono. Que abandonar ou não abandonar, fazer o paciente sentir-se abandonado ou não, seria uma escolha que ele tem, o que justamente configuraria, do lado do analista, a não incidência da castração. Não, o estagiário não tem como evitar o abandono, se ali este é o nome da falta. E se isso não tem a ver com uma impotência, derivada da insuficiência do seu saber até ali, mas com o impossível do saber, tem-se aí causa para o trabalho.

Em certos casos, há efetivamente toda sorte de atuação no momento da comunicação da saída do estagiário: da reação contra o estagiário até a ausência às sessões restantes. Como dissemos, no entanto, isto não deve servir de pretexto para almejar um saber capaz de antecipar, prevenir tais efeitos. Pois a psicanálise, localizando nestes algo que escapa à possibilidade de um saber prévio, o que se teria, na prática, é o encobrimento de tais efeitos. É o que se verifica, por exemplo, quando o estagiário atribui ao fato de que sua saída já estava prevista a ausência de efeitos da mesma. O que se passa, de fato, é que a adesão a esta fórmula implica a não escuta do que venha a ser endereçado a ele nesta hora. Mais uma vez se trata aí de não querer saber do que lhe escapa. Não querer saber que deriva de se tomar o que está aí em jogo no sentido da impotência e não do impossível a que se dirige a psicanálise. Nossa conclusão é que o modo como verificamos se passar esta experiência, para além do que é próprio à posição neurótica, carrega a marca de ser uma clínica inserida no contexto de uma formação universitária.

Recebido em 8/1/2009. Aprovado em 20/8/2009. 


\section{REFERÊNCIASS}

DARRIBA, V. (2003) O conceito psicanalítico e a problematização da realidade "fora de nós" Psychê: revista de psicanálise, ano VII, n.11. São Paulo: Unimarco.

. (2007) Pensando o trabalho de supervisão em psicanálise na universidade. Pulsional. Revista de Psicanálise (São Paulo), v. 1, p.32-39.

FREUD, S. (1990) Edição standard brasileira das obras psicológicas completas de Sigmund Freud. Rio de Janeiro: Imago.

(1919 [1918]) “Sobre o ensino da psicanálise nas universidades”, v.XVII, p.215-220.

(1933 [1932]) “Novas conferências introdutórias sobre psicanálise", v.XXII, p.11-220.

(1937) “Análise terminável e interminável”, v.XXIII, p.239-287.

KOYRÉ, A. (1961/1991) "Da influência das concepções filosóficas sobre a evolução das teorias científicas”, in Estudos de história do pensamento filosófico. Rio de Janeiro: Forense Universitária.

. (1961/1991) “Do mundo do 'mais-ou-menos' ao universo da precisão”, in Estudos de história do pensamento filosófico. Rio de Janeiro: Forense Universitária.

. (1966/1991) "As origens da ciência moderna: uma nova interpretação”, in Estudos de história do pensamento científico. Rio de Janeiro: Forense Universitária.

LACAN, J. (1966) "A ciência e a verdade”, in Escritos. Rio de Janeiro: Jorge Zahar.

(1969-70/1992) O seminário livro 17: 0 avesso da psicanálise. Rio de Janeiro: Jorge Zahar.

LO BIANCO, A. C. (2006) “Apresentação”, in LO BIANCO, A. C. (Org.). Freud não explica: a psicanálise nas universidades. Rio de Janeiro: Contra Capa.

MAURANO, D. (2006) “Um estranho no ninho ou a psicanálise na universidade”, in JORGE, M. A. C. (Org.). Lacan e a formação do psicanalista. Rio de Janeiro: Contra Capa.

MILLER, J.-A. (1997) “A psicanálise na universidade”, in MILLER, J.- A. Lacan elucidado: palestras no Brasil. Rio de Janeiro: Jorge Zahar.

MILNER, J. C. (1991) “Lacan et la science moderne”, in AVTONOMOVA, N. [et al.]. Lacan avec les philosophes. Paris: Albin Michel.

. (1996) A obra clara: Lacan, a ciência, a filosofia. Rio de Janeiro: Jorge Zahar.

POPPER, K. (1972/1982) Conjecturas e refutações. Brasília: Editora UNB.

Vinicius Anciães Darriba

vdarriba@,centroin.com.br 